\title{
Papers
}

\section{Treatment of Indian visceral leishmaniasis with single or daily infusions of low dose liposomal amphotericin B: randomised trial}

\author{
Shyam Sundar, G Agrawal, Madhukar Rai, M K Makharia, Henry W Murray
}

\begin{abstract}
Objective To test short course, low dose liposomal amphotericin B as single or daily infusion treatment in Indian visceral leishmaniasis (kala-azar).

Design Randomised, open label study.

Setting Inpatient unit for leishmaniasis in Bihar, India.

Participants 91 adults and children with splenic aspirate positive for infection.

Interventions Total dose of $5 \mathrm{mg} / \mathrm{kg}$ of liposomal amphotericin B given as a single infusion $(n=46)$ or as once daily infusions of $1 \mathrm{mg} / \mathrm{kg}$ for five days $(\mathrm{n}=45)$.

Main outcome measures Clinical and parasitological cure assessed 14 days after treatment and long term definitive cure (healthy, no relapse) at six months. Results All but one person in each group had an initial apparent cure. During six months of follow up, three patients in the single dose group and two in the five dose group relapsed. Complete response (definitive cure) was therefore achieved in 84 of 91 subjects (92\%): 42 of 46 patients in the single dose group (91\%, 95\% confidence interval $79 \%$ to $98 \%$ ) and 42 of 45 in the five dose group (93\%, 82\% to $99 \%$ ). Response rates in the two groups were not significantly different.

Conclusion Low dose liposomal amphotericin B (5 $\mathrm{mg} / \mathrm{kg}$ ), given either as a five day course or as a single infusion, seems to be effective for visceral leishmaniasis and warrants further testing.
\end{abstract}

\section{Introduction}

Up to half of the world's cases of visceral leishmaniasis (kala-azar) occur in India, and about 90\% of Indian patients live in the state of Bihar. ${ }^{2}$ In the past five years, pentavalent antimony has become ineffective for treating visceral leishmaniasis in Bihar and other drugs have to be used. ${ }^{34}$ Alternative effective treatments include oral miltefosine for 28 days (now completing phase III testing), ${ }^{4}$ daily injections of aminosidine for 21 days, ${ }^{6}$ infusions of conventional amphotericin B given daily for 20 days or on alternate days for 30 days, ${ }^{4}$ and short courses of infusions of a lipid formulation of amphotericin B. ${ }^{4-12}$ Although these treatments have a cure rate of over $90 \%$, the drugs are still under evaluation and either have a prolonged or difficult to tolerate regimen or are prohibitively expensive. ${ }^{4}$

Recently, we tested low dose liposomal amphotericin B in Indian patients in Bihar in whom antimony had failed..$^{13} \mathrm{~A}$ short course, five day treatment regimen consisting of 0.75 or $1.5 \mathrm{mg} / \mathrm{kg} /$ day (total doses 3.75 and $7.5 \mathrm{mg} / \mathrm{kg}$ ) induced long term cure in $89 \%$ and $93 \%$ of patients, respectively. Increasing the dose to 3 $\mathrm{mg} / \mathrm{kg}$ /day (total dose $15 \mathrm{mg} / \mathrm{kg}$ ), which is in the range used in most previous trials, ${ }^{10-12}$ gave a $97 \%$ cure rate. $^{13}$

We conducted a pilot study to determine whether our five day regimen could be abbreviated further. Patients were treated with a low total dose $(5 \mathrm{mg} / \mathrm{kg})$, which was divided and administered over five days or given as a single infusion.

\section{Participants and methods}

\section{Entry and exclusion criteria}

This open label study was carried out at the Kala-Azar Medical Research Centre in Muzaffarpur, Bihar, where visceral leishmaniasis caused by Leishmania donovani is endemic. It was approved by the ethics committee of the Institute of Medical Sciences, Banaras Hindu University, Varanasi.

Patients of any age with visceral leishmaniasis caused by $L$ donovani were eligible if they had symptoms or signs of the disease (fever, weight loss, splenomegaly) and parasites were found by microscopy in a splenic aspirate smear. ${ }^{9}$ Patients were excluded if they were pregnant or breast feeding, HIV positive, had a serious concurrent infection such as tuberculosis or bacterial pneumonia, or if they had a granulocyte count $<1 \times 10^{9} /$, haemoglobin concentration $<40 \mathrm{~g} / \mathrm{l}$, or platelet count $<40 \times 10^{9} / \mathrm{l}$. Eight patients were excluded by these criteria.

\section{Trial procedures and treatment}

After completing baseline testing (standard haematological and biochemistry profiles, urine analysis, chest radiography, electrocardiography, testing for anti-HIV by ELISA, and malaria smear) ${ }^{9}$ and providing written informed consent (from parent or guardian for children), participants were randomised by sealed envelope to receive $5 \mathrm{mg} / \mathrm{kg}$ of liposomal amphotericin (AmBisome, NeXstar, Paris) as a single infusion or
Kala-Azar Medical
Research Centre,
Banaras Hindu
University,
Department of
Medicine, Institute
of Medical Sciences,
Varanasi-211005,
India
Shyam Sundar
professor
G Agrawal
resident
Madhukar Rai
lecturer
M K Makharia
medical officer
Department of
Medicine, Weill
Medical College of
Cornell University,
New York NY
10021, USA
Henry W Murray
professor
Correspondence to:
S Sundar
shyams_vns@
satyam.net.in
BMJ 2001;323:419-22 
as once daily infusions of $1 \mathrm{mg} / \mathrm{kg}$ for five consecutive days. An independent statistician prepared the randomisation envelopes using a computer based random number generator. The study staff opened consecutively numbered envelopes containing the treatment assignment after eligible patients fulfilled the entry criteria.

Treatment was started within three days after splenic aspiration. The dose was given as a 60 minute intravenous infusion with no pretreatment with antipyretic drugs. ${ }^{13}$ Patients were examined daily and remained in the unit until 14 days after the last infusion, at which time splenic aspiration and laboratory evaluation were repeated. We graded parasite density scores for aspirates taken before and after treatment in a blinded fashion using a conventional logarithmic scale of 0 (no parasites per 1000 oil immersion fields) to $>6(>100$ amastigotes per field). ${ }^{9}$ Since we could not rationalise giving the single dose group subjects four additional placebo infusions, clinicians caring for the patients were not blinded to the treatment given.

We defined apparent cure 14 days after treatment ended as absence of fever, clinical improvement, reduction in spleen size, and a splenic aspirate score of 0 (apparent parasitological cure). ${ }^{9}{ }^{13}$ Definitive cure, assessed after six months of follow up, was defined as being healthy with no signs or symptoms of relapse. ${ }^{9} 13$

\section{Statistical analysis}

We compared response rates in the treatment groups by Fisher's exact test and calculated exact binomial

Table 1 Clinical and laboratory results at baseline and after treatment in 91 patients with visceral leishmaniasis. Values are mean (SE) unless stated otherwise

\begin{tabular}{|c|c|c|c|c|}
\hline & \multicolumn{2}{|c|}{ Single dose $(n=46)$} & \multicolumn{2}{|c|}{5 daily doses $(n=45)$} \\
\hline & Day 0 & Day $15^{*}$ & Day 0 & Day $19^{*}$ \\
\hline Age (years)† & \multicolumn{2}{|c|}{$17(2)$} & \multicolumn{2}{|c|}{$18(2)$} \\
\hline No $(\%)$ of men & \multicolumn{2}{|c|}{$30(65)$} & \multicolumn{2}{|c|}{$29(64)$} \\
\hline No (\%) previously given antimony & \multicolumn{2}{|c|}{$22(48)$} & \multicolumn{2}{|c|}{$14(31)$} \\
\hline Duration of illness (months) & \multicolumn{2}{|c|}{$3.6(0.4)$} & \multicolumn{2}{|c|}{$3.3(0.5)$} \\
\hline Splenic aspirate score & $1.8(0.1)$ & $0.2(0.02)$ & $2.0(0.20)$ & $2(0.02)$ \\
\hline Weight (kg) & $27(2)$ & $27(2)$ & $29(2)$ & $30(2)$ \\
\hline Spleen size $(\mathrm{cm})$ & $7.8(0.6)$ & $3.0(0.4)$ & $7.2(0.7)$ & $3.2(0.5)$ \\
\hline Haemoglobin $(\mathrm{g} / \mathrm{l})$ & $70(3)$ & $89(2)$ & $78(2)$ & $97(2)$ \\
\hline White blood cells $\left(\times 10^{9} / l\right)$ & $3.6(0.3)$ & $6.3(0.3)$ & $3.8(0.2)$ & $7.0(0.4)$ \\
\hline Platelet count $\left(\times 10^{9} / \mathrm{I}\right)$ & $121(7)$ & $247(12)$ & $153(10)$ & $292(15)$ \\
\hline Blood urea nitrogen $(\mathrm{mmol} / \mathrm{l})$ & $3.6(0.4)$ & $3.9(0.4)$ & $3.6(0.4)$ & $3.9(0.4)$ \\
\hline Creatinine $(\mu \mathrm{mol} / \mathrm{l})$ & $62(3.5)$ & $62(2.7)$ & $62(3.5)$ & $62(2.7)$ \\
\hline
\end{tabular}

*Responses were measured 14 days after last treatment—day 15 for single dose and day 19 for five dose group.

$\nmid 24$ participants in each group were children ( $\leqslant 12$ years old).

Table 2 Response to liposomal amphotericin B in 91 patients

\begin{tabular}{|c|c|c|}
\hline & Single dose & Five dose \\
\hline Regimen & $5 \mathrm{mg} / \mathrm{kg} \times 1$ & $1 \mathrm{mg} / \mathrm{kg} /$ day $\times 5$ \\
\hline No of participants & 46 & 45 \\
\hline No completing treatment & 46 & 45 \\
\hline No in whom treatment failed & 1 & 1 \\
\hline No with apparent cure ${ }^{*}$ & 45 & 44 \\
\hline No with relapses & 3 & 2 \\
\hline No with definitive cure† & 42 & 42 \\
\hline Rate of cure $(\%, 95 \% \mathrm{Cl}) \neq$ & 91 (79 to 98) & 93 (82 to 99$)$ \\
\hline
\end{tabular}

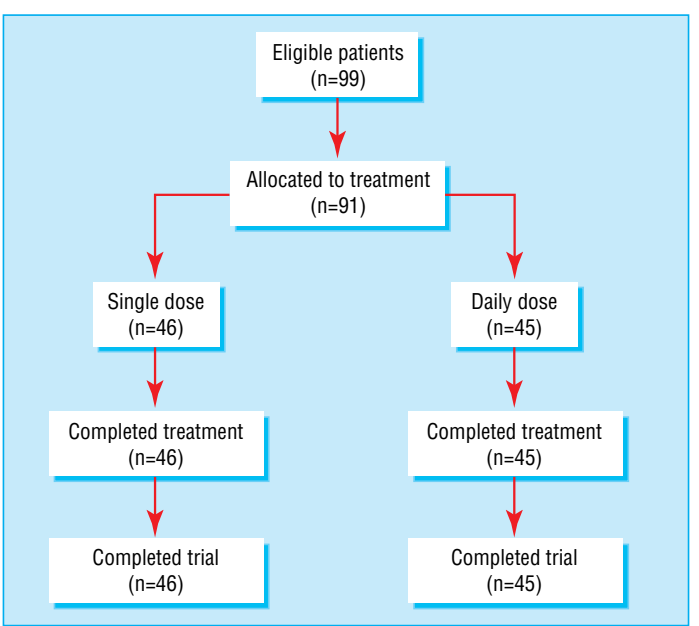

Flow of participant through trial

95\% confidence intervals for the individual proportions responding to each treatment regimen. The objective of this study was to gather preliminary data on the relative efficacy of two treatments that would, if the results warranted it, inform the design of a more precise trial with appropriate statistical power.

\section{Results}

Patient characteristics and initial responses

The figure shows the flow of participants through the trial, and table 1 summarises the clinical features at entry to the study. Thirty six subjects had not responded to pentavalent antimony (sodium antimony gluconate, $20 \mathrm{mg} / \mathrm{kg}$ per day for $\geqslant 28$ days $^{39}$ ); none had received amphotericin $B$. The groups were well matched except for haemoglobin concentration and platelet count (table 1).

At entry, all 46 patients in the single dose group and 43 of 45 in the five dose group had fever. Seven days after treatment started, 45 of the single dose group and 43 of the five dose group had no fever, and mean duration of fever was identical in the two groups (2.6 (0.3) v 2.6 (0.4) days). At evaluation, 14 days after the last amphotericin infusion (table 2), none of the 91 participants had fever and all but one in each group had no parasites in splenic aspirate smears and fulfilled the criteria for apparent cure. One patient in each group had scanty parasites in the repeat aspirate smear and their treatment was designated as a failure. Compared with baseline, patients had reduced spleen size and increased white blood cell count, haemoglobin concentration, and platelet count (table 1).

\section{Adverse reactions}

Twenty four $(52 \%)$ patients in the single dose group and 20 (44\%) in the five dose group had no reaction during or after any infusion. In the remaining patients, reactions were mainly mild, related to the infusion (typical of reactions associated with amphotericin B), and seldom persisted beyond one or two hours after the end of the infusion. In the single dose group, three patients experienced increased temperature alone, one chills alone, and 18 both; two patients vomited once. In the five dose group, four patients had at least one episode of higher fever alone, one chills alone, and 18 both; two had brief vomiting and two had transient 
back pain. Blood urea nitrogen and creatinine concentrations did not change from day 0 in either group (table 1).

\section{Outcome and retreatment}

We followed all apparently cured patients for six months after treatment. ${ }^{3}{ }^{13}$ Five patients had asymptomatic relapses that were confirmed by microscopy (three in single dose group, two in five dose group, table 2). All other participants were asymptomatic, appeared healthy, and were judged to have a definitive cure. Thus, overall, liposomal amphotericin $(5 \mathrm{mg} / \mathrm{kg}$ ) cured $92 \%$ of patients (84/91), 91\% (95\% confidence interval $79 \%$ to $98 \%$ ) of those treated with a single infusion and $93 \%(82 \%$ to $99 \%)$ of those who received five daily infusions of $1 \mathrm{mg} / \mathrm{kg}$ (table 2).

The five patients who relapsed and the two initial non-responders were retreated with amphotericin B deoxycholate (15 alternate day infusions of $1 \mathrm{mg} / \mathrm{kg}$ ). All responded and were considered cured six months later.

\section{Discussion}

In this uncontrolled, observational pilot study, we found that low dose liposomal amphotericin induced rapid resolution of fever, prompt clinical improvement, and an overall cure rate of $92 \%$. We found no evidence that delivering the total dose of $5 \mathrm{mg} / \mathrm{kg}$ as a single infusion was less effective than splitting the dose over five days. However, the small sample size means that the study did not have enough power to prove the equivalence of these two regimens.

A second limitation of the study is that clinical assessment of the initial and six month responses to treatment was not blinded. Nevertheless, the definition of initial cure required the splenic aspirate smear to be free of parasites on microscopy, and this test was done blinded. In addition, the clinical presentation of relapse is not usually affected by previous treatment, and relapse was objectively confirmed in a splenic aspirate.

\section{Resistance}

Another issue is whether patients who relapse or do not respond to low dose treatment could develop resistance to amphotericin $\mathrm{B}$. Our approach is to retreat patients in whom treatment fails with conventional amphotericin B. ${ }^{43}$ Although the results are limited, none of the 13 patients who failed to respond to low dose liposomal amphotericin $\mathrm{B}^{13}$ or the 32 who did not respond to short course, low dose amphotericin B lipid complex treatment ${ }^{4}$ have shown clinical resistance to amphotericin $\mathrm{B}$.

\section{Cost of treatment}

The principal rationale for testing low or single dose regimens is to identify a treatment that is not only effective and convenient but affordable. Commercially available lipid formulations of amphotericin B are expensive, and the cost of even short course or low dose regimens ${ }^{41014}$ are an insurmountable obstacle in the developing world. ${ }^{1}$ For example, US average wholesale prices for the various lipid formulations of amphotericin B are $\$ 188$ (£125) per $50 \mathrm{mg}$ vial for AmBisome (liposomal), \$93 per $50 \mathrm{mg}$ for Amphotec (cholesterol dispersion), and \$194 per $100 \mathrm{mg}$ for Abelcet (lipid complex). ${ }^{15}$ The regimen for liposomal

\section{What is already known on this topic}

Pentavalent antimony is now ineffective against visceral leishmaniasis in India

Liposomal amphotericin B is effective but high cost prohibits its use in developing countries

\section{What this study adds}

Liposomal amphotericin B $(5 \mathrm{mg} / \mathrm{kg})$, given as a single infusion or five daily infusions of $1 \mathrm{mg} / \mathrm{kg}$, cured $92 \%$ of patients

If proved effective in larger trials, low dose regimens could make the drug more affordable

amphotericin B approved by the US Federal Drugs Administration for visceral leishmaniasis consists of 3 $\mathrm{mg} / \mathrm{kg}$ given on days 1-5, 14, and 21 (total dose, 21 $\mathrm{mg} / \mathrm{kg}){ }^{16}$ AmBisome currently costs about $\$ 173$ per $50 \mathrm{mg}$ in India, and in a $25 \mathrm{~kg}$ patient the regimen equates to about $\$ 1900$. The regimen used in our study, which produced cure rates of $92 \%$ rather than $97 \%$, would cost $\$ 519$. This is more affordable but still too high.

Amphotericin B deoxycholate (Fungizone) is cheaper than the lipid formulations (US wholesale price $\$ 17$ per $50 \mathrm{mg}$ vial, retail price in India $\$ 6$ per 50 $\mathrm{mg}$ vial). ${ }^{4}{ }^{14}$ It is now first line treatment for visceral leishmaniasis in Bihar because of antimony resistance and produces cure rates of $>95 \%$ in patients who complete treatment. However, the regimens are prolonged and therefore expensive, require daily infusions for 20 days or (more usually) on alternate days over 30 days, and are not always well tolerated. ${ }^{4}$ Short course regimens using drugs such as AmBisome or Abelcet, ${ }^{9}{ }^{13}$ which also seem to produce fewer adverse reactions than the deoxycholate form, ${ }^{4}{ }^{13}$ are therefore attractive.

Although hospital stay and costs can be appreciably reduced by short courses and especially single dose regimens, ${ }^{4}{ }^{14}$ these savings do not offset the cost of the drug in countries such as India, where hospital charges are low. If definitive trials establish the efficacy of our low dose regimen, drug companies will have to cut prices for the potential benefits to be realised.

Contributors: SS participated in designing the study, collecting the data, and writing the paper and was the principal investigator, $\mathrm{He}$ is guarantor of the paper. GA, MR, and MKM were involved in clinical assessment of patients and collecting data. HWM collaborated on the design of the study, was responsible for interpreting data, and helped with writing the paper.

Funding: The Sitaram Memorial trust provided partial financial support for this study, and NeXstar provided the AmBisome. NeXstar had no role in gathering or interpreting the data or in deciding if the study was to be submitted for publication.

Competing interests: SS has been reimbursed by NeXstar for attending several conferences. SS has also served as principal investigator for two trials of AmBisome funded by NeXstar in India.

1 Bora D. Epidemiology of visceral leishmaniasis in India. Natl Med J India 1999;12:62-8.

2 Lal S, Saxena NBL, Dhillon GPS. Kala-azar cases and deaths. In: Manual on visceral leishmaniasis (kala-azar) in India. Annexure VII. New Delhi: National Malarial Eradication Programme, 1996:167-77. 
3 Sundar S, More DK, Singh MK, Singh VP, Sharma S, Makharia A, et al. Failure of pentavalent antimony in visceral leishmaniasis in India: report from the center of the Indian epidemic. Clin Infect Dis 2000;31:1104-7.

4 Murray HW. Treatment of visceral leishmaniasis (kala-azar): a decade of progress and future approaches. Int J Infect Dis 2000;4:158-77.

5 Herwaldt BL. Miltefosine: the long-awaited therapy for visceral leishmaniasis? N Engl J Med 1999;341:1840-2.

6 Jha TK, Olliaro P, Thakur CP, Kanyok TP, Singhania BL, Singh IJ, et al. Randomised controlled trial of aminosidine (paromomycin) v sodium stibogluconate for treating visceral leishmaniasis in North Bihar, India. BMJ 1998;361:1200-5.

7 Thakur CP, Singh RK, Hassan SM, Kumar R, Narain S, Kumar A. Amphotericin B deoxycholate treatment of visceral leishmaniasis with newer modes of administration and precautions: a study of 938 cases. newer modes of administration and prec
Trans $R$ Soc Trop Med Hyg 1999:93:319-23.

8 Dietze R, Fagundes S, Brito E, Milan EP, Feitosa TF, Suassana FA, et al. Treatment of kala-azar in Brazil with Amphocil (amphotericin B cholesterol dispersion) for 5 days. Trans $R$ Soc Trop Med Hyg 1995;89: 309-11.

9 Sundar S, Agrawal NK, Sinha PR, Horwith GS, Murray HW. Short-course, low-dose amphotericin B lipid complex therapy for visceral leishmaniasis unresponsive to antimony. Ann Intern Med 1997;127:133-7.

10 Davidson RN, di Martino L, Gradoni L, Giacchino R, Gaeta GB, Pempinello R, et al. Short-course treatment of visceral leishmaniasis with liposomal amphotericin B (AmBisome). Clin Infect Dis 1996;22:938-43.
11 Di Martino L, Davidson RN, Giacchino R, Scotti S, Raimondi F, Castagnola E, et al. Treatment of visceral leishmaniasis in children with liposomal amphotericin B. J Pediatr 1997;131:271-7.

12 Berman JD, Badaro R, Thakur CP, Wasunna KM, Behbehani K, Davidson $\mathrm{R}$, et al. Efficacy and safety of liposomal amphotericin B (AmBisome) for visceral leishmaniasis in endemic developing countries. Bull World Health Organ 1998:76:25-32.

13 Sundar S, Jha TK, Thakur CP, Mishra M, Singh VP, Buffels R. Low dose liposomal amphotericin B (AmBisome) in refractory Indian visceral leishmaniasis-a multicenter study. Am J Trop Med Hyg (in press).

14 Sundar S, Goyal AK, More DK, Singh MK, Murray HW. Ultra-shortcourse amphotericin B lipid complex treatment for antimonyunresponsive Indian visceral leishmaniasis. Ann Trop Med Parasitol 1998;92:755-64.

15 Drug topics redbook. Montavale, NJ: Medical Economics, 1999.

16 Meyerhoff A. US Food and Drug Administration approval of AmBisome (liposomal amphotericin B) for treatment of visceral leishmaniasis. Clin Infect Dis 1999;28:42-8.

17 Thakur CP, Pandey AK, Sinha GP, Roy S, Behbehani K, Olliaro P. Comparison of three treatment regimens with liposomal amphotericin $\mathrm{B}$ (AmBisome) for visceral leishmaniasis in India: a randomized dose-finding study. Trans R Soc Trop Med Hyg 1996;90:319-22.

(Accepted 14 May 2001)

\title{
Commentary: cost and resistance remain issues
}

\author{
Diana N J Lockwood
}

Hospital for

Tropical Diseases,

London

WC1E 6AU

Diana NJ

Lockwood

consultant physician

Diana.Lockwood@

lshtm.ac.uk
Leishmania are inoculated into humans by the bite of infected sandflies. In the Indian subcontinent the infection is anthroponotic; man is the only known reservoir. The close proximity of humans, cows, and sandflies in Indian villages provides ideal conditions for spread of the disease.

Control of the disease depends on controlling sandflies and detecting and treating human disease early. Since the end of the antimalarial campaigns there has been little systematic use of insecticides, and the proposal to ban the use of the cheap and effective dicophane (DDT) poses an extra threat to control measures. Treatment is therefore the mainstay of control. Pentavalent antimonials have been the treatment of choice since the $1920 \mathrm{~s}$, but resistance is increasing in India. Thus there is an urgent need for new drugs. Currently three drugs are being evaluated for visceral leishmaniasis in India, liposomal amphotericin B, paromomycin, and oral miltefosine. ${ }^{1}$

The exclusion criteria used in the study by Sundar et al show the degree of weight loss and the effects of disease and splenomegaly on the haemoglobin, granulocyte, and platelet counts. Splenic aspirate remains the best method of diagnosis. It is simpler and less painful than a bone marrow aspirate and is the only means of assessing the parasitic response to treatment.

This study shows that a one day course of treatment can cure the disease in $90 \%$ of very sick patients. This is good but tantalising news for patients, many of whom are landless peasants. Their earning capacities will have been seriously impaired by their disease. The families' financial losses are increased because relatives have to care for and feed patients while they are in hospital.

Nevertheless, we cannot be sure that a $90 \%$ cure rate would be adequate to prevent the emergence of resistance. Studying drug resistance in leishmaniasis is difficult. Amastigote-macrophage cultures have to be used because there are no molecular markers of resistance. But monitoring drug resistance is important, especially when monotherapy is used in an anthroponotic focus. Perhaps short combined regimens should be developed to ensure that the range of drugs for leishmaniasis remains adequate.

The drug treatment of leishmaniasis highlights the problems of delivering effective drugs to resource poor settings. Paromomycin has been shown to be more effective than antimony, ${ }^{2}$ but the drug has still not yet reached patients. Four years ago, the drug had no manufacturer. An industrial partner has now been found, but the tropical disease research programme at the World Health Organization does not have the funds to complete the comparative studies needed for drug registration.

Liposomal amphotericin remains an extremely expensive drug that no patient or health service in the developing world is ever going to be able to buy, and there are no patient activists to pressurise the manufacturer into providing the drug at an affordable price.

Competing interests: None declared.

Jha TK, Sundar S, Thakur CP, Bachmann P, Karbwang J, Fischer C, et al. Miltefosine, an oral agent, for the treatment of Indian visceral leishmaniasis. N Engl J Med 1999;341:1795-800.

2 Jha TK, Olliaro P, Thakur CPN, Kanyok TP, Singhania BL, Singh IJ, et al. Randomised controlled trial of aminosidine (paromomycin) v sodium stibogluconate for treating visceral leishmaniasis. BMJ 1998:316:1200-5.

\section{Endpiece Learning to die}

Very few men are capable of coming to terms with their own extinction.... It is the hardest task of all to face the lack of cosmic support for what we care about. Socrates, therefore, defines the task of philosophy as "learning to die."

Allan Bloom, The closing of the American Mind, New York: Touchstone Books, 1988 